\title{
The Perspectives of Educators and Learners on E-Learning: A Cross-Sectional Descriptive Study in a Medical School
}

\author{
Kimi Soumya Padhi \\ Govinda Balmuchu iD \\ Partha Sarathi Acharya \\ Sudipta Ranjan Singh \\ Tony Joseph (ID
}

Department of Forensic Medicine and Toxicology, All India Institute of Medical Sciences, Bhubaneswar, Odisha, India
Correspondence: Govinda Balmuchu Department of Forensic Medicine and Toxicology, All India Institute of Medical Sciences, Bhubaneswar, Sijua, Patrapada, Bhubaneswar, Odisha, 751019, India Tel +9/987/293683

Email govindabalmuchu@gmail.com
Purpose: To determine the challenges, effectiveness, level of reception and acceptance of E-learning by students (learners) and faculty (educators) in a medical college during the lockdown period of the COVID-19 pandemic.

Methods: An online questionnaire-based cross-sectional study was conducted among learners and educators at AIIMS, Bhubaneswar, Odisha, India, in the month of August 2020. A total of 203 learners and 24 educators participated in the study. The link of the Google form containing the questionnaire was sent to the students and teachers, and the responses obtained were analyzed with SPSS software (version 20).

Results: Two hundred three MBBS students and twenty-four faculty members participated in the study. In our study, 34.5\% $(n=70)$ learners and $62.5 \%(n=15)$ educators preferred supplementation of E-learning with conventional mode of pedagogy in the future. There was a significant correlation between the convenience and the effectiveness of E-learning. Both learners and educators considered E-learning to be moderately effective. The major problems faced by the educators while conducting online sessions were network issues, difficulty in conducting practicals, lack of controlled environment, and lack of attentiveness by the learners. More than half of the students were satisfied with the E-learning provided by the institute. Educators found E-learning to be moderately convenient, whereas they felt conventional classroom teaching is highly convenient.

Conclusion: Educators and learners were quick to adapt to the online mode of learning but the shift was mired with initial challenges. There is a requirement of capacity building in terms of skill development and digital infrastructure building to ensure seamless and effective E-learning.

Keywords: COVID-19, lockdown, medical education, conventional pedagogy effectiveness

\section{Introduction}

The COVID-19 pandemic has adversely affected people from all walks of life and brought the world to a standstill. ${ }^{1}$ In India, lockdown and social distancing measures were implemented as the strategic approach to flatten the curve and control the transmission cycle of coronavirus. ${ }^{2,3}$ This led to the closure of schools and higher educational institutes and resulted in the paradigm shift in teaching and learning processes ie, the traditional face-to-face mode was replaced by online mode. ${ }^{4,5}$ The conventional method of medical education in India includes conducting lectures using PowerPoint presentations in lecture theatres, practical classes in laboratories of respective departments and demonstration of clinical skills with 
history taking and physical examination at the bedside in hospital wards. During the lockdown period, Educators in our institute availed the online platform (E-learning) to deliver the lectures using video-conferencing tools such as Google Meet, Zoom, Microsoft Teams etc.

E-learning is the use of electronic technology in one form or the other, including the internet as a medium to deliver education to enhance teaching and learning. ${ }^{6}$ With increasing internet penetration, towering number of smart phone users and rising web footprints in India, E-learning as a mode of education has been experiencing steady growth over the past decade. ${ }^{7}$ The ease of accessibility, round the clock availability, convenient timings, personalised study environment have boosted its popularity. ${ }^{8}$ But the lack of digital education, absence of humane touch, poor network connections and aversion to change amongst the practitioners of conventional classroom pedagogy have restricted its potential exponential growth. Medical education in India, though it has undergone small drifts and evolution in pedagogy over the years, it has been almost immune to e-learning. ${ }^{9}$ During the pandemic scenario, in order to ensure continuous and effective delivery of medical education, it is imperative to understand the intricacies, advantages and challenges posed by E-learning to both the educators and the learners in the field of education. Then and only then can we ensure a sustainable and stable medical education model that can withstand global emergencies like a pandemic or any similar crisis. The outcome of this study will help us to address the challenges and formulate and devise an effective E-learning strategy to deliver quality medical education. An effective E-learning strategy might become the harbinger of saltation in medical pedagogy.

The current study aims to assess the perception regarding challenges, effectiveness, level of reception and acceptance of E-learning by Learners and Educators in a medical college during the lockdown period of the COVID-19 pandemic.

\section{Materials and Methods}

\section{Study Design, Setting and Participants}

This study is a cross-sectional online questionnaire-based study conducted at AIIMS (All India Institute of Medical Sciences), Bhubaneswar, in the month of August 2020. The study population included undergraduate students (Learners) pursuing MBBS course and the faculty members (Educators) of the department involved in the MBBS teaching curriculum.

\section{Sample Size Calculation}

The sample size was calculated for the learners based on the response rate of $66 \%$, as reported by the previous study. ${ }^{10}$ Keeping the margin of error at $5 \%$, Confidence Interval at $95 \%$, and population size of 400 , the sample size was calculated as 186 . A sample of 24 faculty members was taken to know the perception of the educators.

\section{Questionnaire Design and Distribution}

Two separate questionnaires (Learners and Educators) were prepared in the Google form after discussion among post-graduate students, revised and edited by the authors. A pilot test was conducted on 25 students and few faculty members to test the validity of the questionnaire. The response was then reviewed, and the questionnaire was finalized as mentioned in Supplementary Material. The link of the google form containing PIS (Participant Information Sheet), Informed Consent, and the questionnaire was sent to the study population satisfying inclusion criteria via e-mail and WhatsApp. On clicking the abovementioned link, the participants were directed to the page displaying the Participant Information Sheet and the Informed Consent. The participants would be directed to the questionnaire section only after agreeing to participate in the study. The questionnaire consisted of both single and multiple response-based questions. The individual response was automatically recorded and stored in Google Drive and then analyzed. The reminders were sent to the participants and the survey links were disabled after ten days. Each participant could submit the response only once from his/her e-mail. The participants could not edit their answers once his/her responses were submitted. The confidentiality and anonymity of the participants were maintained by only collecting their responses and no other personal details.

\section{Ethical Considerations}

The study was carried out after obtaining approval from the Institutional Ethics Committee (Reference: T/IM-NF /FM\&T/20/56). Participation in the survey was on a voluntary basis.

\section{Data Analysis}

The data collected in Google Drive was exported to SPSS software (version 20) for analysis. Qualitative data were 
summarised as frequency and percentage. Proportions were compared by the chi-square test. The Likert scale ranged from strongly disagree, disagree, neutral, agree and strongly agree with the corresponding score of 1, 2, 3, 4, and 5, respectively. ${ }^{11-14}$ The mean score has been divided into three levels [low: 1-2.33, medium: $2.34-3.67$, high: $3.68-5.00]^{15}$ for comparing findings with other studies. The scores 3 and 4 on a Likert scale were considered as positive responses.

\section{Results}

A total of 203 Learners and 24 Educators participated in the online study. Ninety-four (46.3\%) students and seventeen $(70.8 \%)$ faculty members had previous exposure to E-learning.

\section{Responses Given by the Learners}

The most common method used by the educators were Live audio-visual (AV) with PowerPoint presentation (PPT) ie, using video-conferencing tools like Zoom, Google Meet, etc. Learners preferred live audio-visual with PowerPoint presentation with average ratings of 3.89 [Minimum score - 1, Maximum score -5 ]. The response of the Learners regarding the questions related to E-learning has been represented in Table 1.

The most preferred video-conferencing tool was Google Meet (94.6\%) and, smart phone (84.2\%) was the most common device used for attending online classes. The most appropriate duration of a single lecture was 30-40 minutes, and they were most comfortable with $1-$

Table I E-Learning Related Responses by the Learners

\begin{tabular}{|l|c|c|}
\hline Question & Yes & No \\
\hline $\begin{array}{l}\text { Previous exposure of E-learning } \\
(\mathrm{N}=203)\end{array}$ & $94(46.3 \%)$ & $109(53.7 \%)$ \\
\hline $\begin{array}{l}\text { Satisfied with the E-learning provided } \\
\text { by the institution ( } \mathrm{N}=203)\end{array}$ & $116(57.1 \%)$ & $87(42.9 \%)$ \\
\hline $\begin{array}{l}\text { Handouts to be provided prior to class } \\
(\mathrm{N}=203)\end{array}$ & $185(91.1 \%)$ & $18(8.9 \%)$ \\
\hline $\begin{array}{l}\text { Evaluation required of the topics } \\
\text { covered (N = 203) }\end{array}$ & $116(57.1 \%)$ & $87(42.9 \%)$ \\
\hline $\begin{array}{l}\text { Practical classes content to be covered } \\
\text { in E-learning (N = 203) }\end{array}$ & $107(71.4 \%)$ & $58(28.6 \%)$ \\
\hline $\begin{array}{l}\text { Feedback mechanism post E-learning } \\
\text { sessions (N = 203) }\end{array}$ & $157(77.3 \%)$ & $46(22.7 \%)$ \\
\hline
\end{tabular}

3 hours of online sessions in a single day. Most preferred two sessions if the total duration of online classes crosses two hours in a single day. The most convenient timing was $10 \mathrm{am}-12 \mathrm{pm}$, followed by $8 \mathrm{am}-10 \mathrm{am}$. These findings have been depicted in Table 2 .

The Learners (57.1\%) were enthusiastic about being asked regarding evaluation. Most of the participants (Learners) preferred activity/assignment over the traditional examination. For activity/assignment, they showed more interest in making an abstract/summary and preparing questions of the topics covered. For traditional examination-based evaluation, objective structured questions were preferred over subjective questions. Grade-based assessment $(55.7 \%)$ was the most responded method for being assessed over mark-based. Participants felt a lack of in-person communication with peers, direct face-to-face interaction with the educators, and classroom environment as the major factors for missing the traditional pedagogy system. Eighty-seven $(42.9 \%)$ were dissatisfied, and the reasons are illustrated in Figure 1.

More than half of the Learners, 116 (57.1\%) were satisfied with the E-learning because they could access online classes from their home, ease of accessibility, and convenient timings. Those students who were satisfied with the E-learning facility provided by the institute were more likely open to the idea of using E-learning as a supplement to conventional classroom mode of teaching; they also perceived E-learning to be effective as demonstrated in Table 3.

\section{Responses Given by the Educators}

Twenty-two (91.7\%) responded that communication skill was the most essential followed by technological skill for teaching effectively in E-learning. The skill set acquired by them was obtained by attending educational webinars and from their colleagues. They suggested practical sessions/clinical teaching be conducted using pre-recorded video with a demonstration or live demonstration. Most of them were aware of cyber-bullying, and one of the Educator faced the issue of cyber-bullying. The response provided by the Educators has been depicted in Table 4.

During the lockdown, teachers delivered the lectures using video-conferencing tools and they preferred it over the other methods. Google Meet and Zoom were the most common streaming platform used by them. Fifteen $(62.5 \%)$ of the teachers conducted assessments following E-learning sessions. They preferred conventional classroom teaching over online mode. The factors related to 
Table 2 Descriptive Data Regarding E-Learning by the Learners

\begin{tabular}{|c|c|c|c|c|}
\hline Question & & & & \\
\hline Most preferred app for accessing E-learning $(\mathrm{N}=203)$ & $\begin{array}{l}\text { Google Meet } \\
192(94.6 \%)\end{array}$ & $\begin{array}{l}\text { Zoom } \\
6 \text { (2.96\%) }\end{array}$ & $\begin{array}{l}\text { GoToMeeting } \\
3(1.48 \%)\end{array}$ & $\begin{array}{l}\text { Others } \\
2(0.96 \%)\end{array}$ \\
\hline Device used to access E-learning $(\mathrm{N}=203)$ & $\begin{array}{l}\text { Smart phone } \\
\text { |7| (84.2\%) }\end{array}$ & $\begin{array}{l}\text { Laptop } \\
4 \mathrm{I}(20.2 \%)\end{array}$ & $\begin{array}{l}\text { Tablet } \\
40(19.7 \%)\end{array}$ & $\begin{array}{l}\text { Desktop } \\
3(1.5 \%)\end{array}$ \\
\hline Appropriate duration of a single lecture $(\mathrm{N}=203)$ & $\begin{array}{l}30-40 \mathrm{~min} \\
102(50.2 \%)\end{array}$ & $\begin{array}{l}40-60 \mathrm{~min} \\
79(38.9 \%)\end{array}$ & $\begin{array}{l}20-30 \mathrm{~min} \\
20(9.9 \%)\end{array}$ & $\begin{array}{l}20 \mathrm{~min} \\
2(1 \%)\end{array}$ \\
\hline Total duration of E-learning in a day $(\mathrm{N}=203)$ & $\begin{array}{l}2-3 \mathrm{hr} \\
98(48.2 \%)\end{array}$ & $\begin{array}{l}\mathrm{I}-2 \mathrm{hr} \\
8 \mathrm{I}(39.9 \%)\end{array}$ & $\begin{array}{l}3-4 \mathrm{hr} \\
20(9.9 \%)\end{array}$ & $\begin{array}{l}\text { Others } \\
4(2 \%)\end{array}$ \\
\hline Convenient timing $(N=203)$ & $\begin{array}{l}10 \mathrm{am}-12 \mathrm{pm} \\
147(72.4 \%)\end{array}$ & $\begin{array}{l}8 \mathrm{am}-10 \mathrm{am} \\
27(13.3 \%)\end{array}$ & $\begin{array}{l}2 \mathrm{pm}-4 \mathrm{pm} \\
25(12.3 \%)\end{array}$ & $\begin{array}{l}\text { Others } \\
4(2 \%)\end{array}$ \\
\hline Number of sessions for online classes (if total duration more than $2 \mathrm{hrs}$ ) $(\mathrm{N}=120)$ & $\begin{array}{l}2 \text { sessions } \\
71(59.2 \%)\end{array}$ & $\begin{array}{l}3 \text { sessions } \\
4 \mid(34.2 \%)\end{array}$ & $\begin{array}{l}\text { I session } \\
8(6.7 \%)\end{array}$ & \\
\hline
\end{tabular}

E-learning and its effectiveness have been graded by the Educators, which has been illustrated in Table 5 .

The major problems faced by them while conducting online sessions were network issues and difficulty in conducting practical classes. However, $62.5 \%(\mathrm{n}=15)$ of them agreed to the idea of using E-learning for supplementing the conventional classroom mode of teaching. The experience of E-learning was significantly associated with its perception of effectiveness. Similarly, those who were convenient with the online mode of teaching were more likely to find E-learning more effective. These findings have been summarised in Table 6.

The suggestions given by the Learners and Educators to improve E-learning have been depicted in Table 7 . Educators having minimal experience and expertise in E-learning faced teething problems like coordinating and organizing e-classes along with managing participants, maneuvering online platforms and selecting modes of assessment and mode of delivery.

\section{Discussion}

E-learning in medical education is evolving owing to its persistent dependence on conventional pedagogy in the medical institution. The halt in the continuity of medical education precipitated by the pandemic led to an abrupt shift from conventional pedagogy to E-learning. The conduction of classes through online medium resulted in some teething problems as this was a venture into uncharted territory. The present study highlights the perception of the Learners and Educators towards E-learning and the attempt to describe the difficulties faced in E-learning by the faculties and undergraduate students of AIIMS, Bhubaneswar during the lockdown period.

In our study, $46.3 \%$ students and $70.8 \%$ faculty members had previous exposure of E-learning. This was consistent with the study about awareness of online learning of undergraduates during COVID-19 in Sri Lanka, ${ }^{16}$ where $49.8 \%$ students had prior experience of online learning. In contrast to our

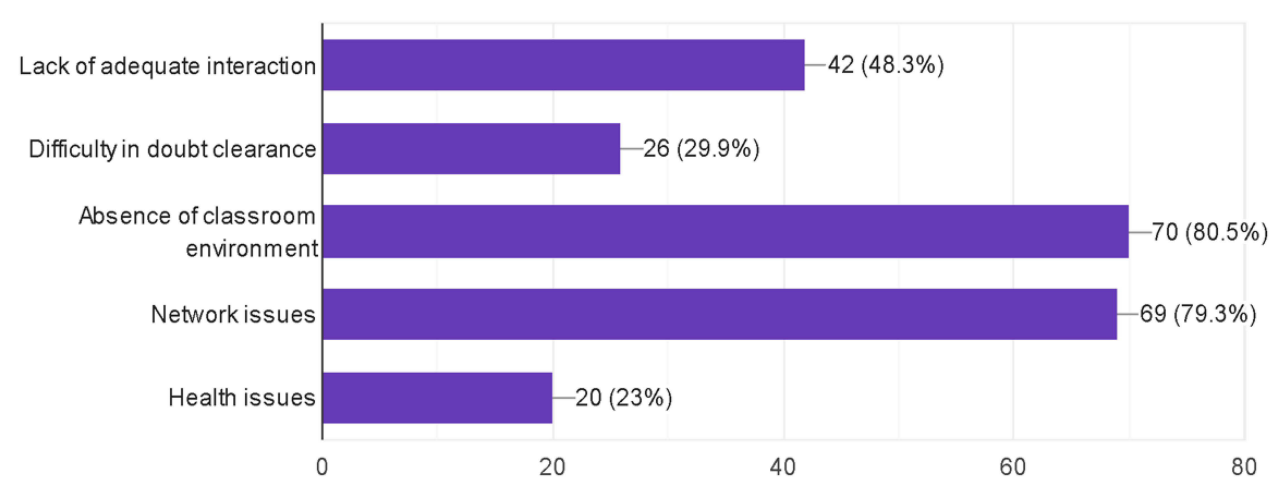

Figure I Reasons for dissatisfaction with E-learning (Multiple response-based answer). 
Table 3 Cross-Tabulation of Satisfied and Dissatisfied Students with Effectiveness of E-Learning and Using It as Supplement

\begin{tabular}{|l|c|c|c|}
\hline \multirow{2}{*}{} & \multicolumn{2}{|c|}{ Satisfied with E-Learning } & \multirow{2}{*}{ p-value } \\
\cline { 2 - 3 } & Yes & No & \\
\hline \multicolumn{2}{|l|}{} \\
\hline Use E-learning as supplement & \multirow{2}{*}{0.01} \\
Yes & 48 & 22 & \\
\hline Perception regarding effectiveness of E-learning \\
\hline Effective & 47 & 18 & 0.003 \\
Not effective & 69 & 69 & \\
\hline
\end{tabular}

Notes: p-value was calculated using chi-square test; [Agree and strongly agree taken as yes for use of E-learning as supplement; Score 4 and 5 - regarded as effective].

study, only $10.8 \%$ of the students had previously attended online classes in a study conducted in Nepal. ${ }^{17}$ Similarly, only $40.2 \%$ faculty had previous exposure to online learning in a study conducted in Egypt. ${ }^{18}$ The difference may be due to the small sample size of Educators in our study.

Ninety-five (46.8\%) students and nine (37.5\%) faculty wanted practical class content to be delivered through online sessions (excluding the response-maybe). This was in contrast with the study by Gupta et $\mathrm{al}^{17}$ where only $4 \%$ students agreed that practical/clinical simulation exercise to be conducted through an online class. Similarly, Sahoo et $\mathrm{al}^{19}$ observed that only $16 \%$ of the teachers were supportive of delivering practical class content through online mode of learning. Practical sessions include interaction between the student and the patient, which could not be done through E-learning medium. However, basic clinical skills including physical examination could be streamed live or sent prerecorded. ${ }^{20}$

One hundred sixteen $(57.1 \%)$ students were satisfied with the E-learning facility provided by the institute. Similarly, the study in China $^{13}$ revealed that students were highly satisfied with the online learning services available with a mean score of 3.74 and in Indonesia ${ }^{12}$ with a mean score of 3.71 . Another study ${ }^{21}$ showed overall satisfaction of using the E-learning and virtual classes with a mean of 5.10 [score ranging from 1 to 6]. In our study, students who were satisfied with the E-learning considered it to be the effective mode of learning and teaching. The dissatisfaction of the students was due to network issues, technical issues, long duration of lectures and improper schedule as highlighted in the suggestion box.

Educators considered E-learning to be moderately convenient with a mean score of 3.37 , whereas they considered conventional classroom mode of teaching to be highly convenient with a mean score of 4.45. There was a significant correlation between the convenience of E-learning with its effectiveness ( $p$-value $<0.001$ ) for the Educators. Learners and Educators considered E-learning to be moderately effective with mean scores of 3.10 and 3.33, respectively. These findings were consistent with another study ${ }^{13}$ where students perception of effectiveness was high with a mean score value of 3.77 .

Educators preferred conventional classroom teaching over online mode. This finding is consistent with several Indian studies ${ }^{22-24}$ as well as in studies of other countries. $^{11,25,26}$ However, in our study seventy $(34.5 \%)$ Learners and fifteen (62.5\%) Educators agreed to the use of E-learning for supplementing conventional classroom mode of teaching. Many studies showed similar results where students preferred blended method of teaching ie, a combination of face-to-face teaching and E-learning. ${ }^{11,22,27,28}$

According to the majority of the participants, network issues were the most common impeding factor in the smooth conduction of E-learning. This finding was consistent with other studies. ${ }^{16,17,26,29}$ This can be solved if live online sessions are followed by uploading of the recorded session in the common online platform. So,

Table 4 E-Learning Related Response by the Educators

\begin{tabular}{|c|c|c|c|}
\hline \multicolumn{2}{|l|}{ Question } & Yes & No \\
\hline \multicolumn{2}{|l|}{ Previous exposure of E-learning ( $\mathrm{N}=24)$} & $17(70.8 \%)$ & $07(29.2 \%)$ \\
\hline \multirow[t]{2}{*}{ Evaluation methods used in E-learning to be used for } & Formative Assessment & $21(87.5 \%)$ & $03(12.5 \%)$ \\
\hline & Summative Assessment & $07(29.2 \%)$ & $17(70.8 \%)$ \\
\hline \multicolumn{2}{|l|}{ Practical classes content to be included in E-learning module } & $20(83.3 \%)$ & $04(16.7 \%)$ \\
\hline \multicolumn{2}{|l|}{ Feedback mechanism post E-learning sessions } & $22(91.7 \%)$ & $02(8.3 \%)$ \\
\hline \multicolumn{2}{|l|}{ Awareness about the concept of cyber bullying } & $17(70.8 \%)$ & $07(29.2 \%)$ \\
\hline
\end{tabular}


Table 5 Grading of Various Responses by the Educators

\begin{tabular}{|c|c|c|}
\hline Score Range & Responses & $\begin{array}{l}\text { Mean } \\
\text { Score }\end{array}$ \\
\hline \multicolumn{3}{|c|}{ Experience and convenience of the Educators in E-learning } \\
\hline $\begin{array}{l}0- \\
\text { No experience } \\
\text { I - Highly } \\
\text { satisfactory }\end{array}$ & $\begin{array}{l}\text { Experience of teaching in } \\
\text { E-learning }\end{array}$ & 3.25 \\
\hline $\begin{array}{l}\text { I - Very weak } \\
5 \text { - Very strong }\end{array}$ & Overall Proficiency in E-learning & 3.66 \\
\hline \multirow{2}{*}{$\begin{array}{l}\text { I - Least } \\
\text { convenient } \\
5 \text { - Most } \\
\text { convenient }\end{array}$} & $\begin{array}{l}\text { Teaching in conventional } \\
\text { classroom }\end{array}$ & 4.45 \\
\hline & Teaching in online mode & 3.37 \\
\hline \multicolumn{3}{|c|}{ Skills required to make E-learning effective } \\
\hline \multirow{4}{*}{$\begin{array}{l}0-\text { Not required } \\
5-\text { Must required }\end{array}$} & Communication skill & 4.20 \\
\hline & Technological skill & 3.91 \\
\hline & Assessment \& Evaluation skill & 3.54 \\
\hline & Time Management skill & 3.45 \\
\hline \multicolumn{3}{|c|}{ Preferred method of teaching in E-learning } \\
\hline \multirow{2}{*}{$\begin{array}{l}\text { I - Least } \\
\text { preferred } \\
5 \text { - Most } \\
\text { preferred }\end{array}$} & Live AV streaming with PPT & 4.16 \\
\hline & Recorded AV with PPT & 3.45 \\
\hline \multicolumn{3}{|c|}{ Factors affecting the effectiveness of E-learning } \\
\hline \multirow{5}{*}{$\begin{array}{l}0-\text { No effect } \\
5 \text { - Maximum } \\
\text { effect }\end{array}$} & Difficulty in conducting practicals & 4.08 \\
\hline & Internet connectivity issues & 4.04 \\
\hline & $\begin{array}{l}\text { Face-to-face interaction with } \\
\text { students }\end{array}$ & 3.75 \\
\hline & Attentiveness of students & 3.66 \\
\hline & Lack of supervision & 3.25 \\
\hline \multicolumn{3}{|c|}{ Perception of Educators regarding effectiveness of E-learning } \\
\hline $\begin{array}{l}\text { I - Ineffective } \\
5 \text { - Highly } \\
\text { effective }\end{array}$ & $\begin{array}{l}\text { E-learning is effective mode of } \\
\text { pedagogy }\end{array}$ & 3.33 \\
\hline
\end{tabular}

Abbreviations: AV, audio-visual; PPT, PowerPoint presentation.

even if students miss due to some technical glitch or unavoidable circumstance, he or she can view the lecture later on at their convenient time. This will actually benefit the students even without overburdening the teachers.

In our college, both synchronous (live or real-time) and asynchronous (recorded) E-learning was implemented
Table 6 Correlation Between Various Factors Related to the Educators

\begin{tabular}{|l|c|c|}
\hline Correlation Between & $\begin{array}{c}\text { Spearman's } \\
\text { Coefficient }\end{array}$ & p-value \\
\hline Experience and Technological skill & $\rho=0.283$ & 0.180 \\
Experience and Proficiency & $\rho=0.208$ & 0.32 \\
Experience and Effectiveness & $\rho=0.597^{* *}$ & 0.002 \\
Convenience and Effectiveness & $\rho=0.657^{* *}$ & 0.000 \\
\hline
\end{tabular}

Notes: ${ }^{*}$ Correlation is significant at the 0.01 level (2-tailed); $\rho$, Spearman's coefficient.

Table 7 Suggestions Provided by the Learners and Educators

\begin{tabular}{|c|c|}
\hline Learners & Educators \\
\hline $\begin{array}{l}\text { - The topics should be covered } \\
\text { in multiple sessions with shorter } \\
\text { duration instead of single session } \\
\text { with longer duration. } \\
\text { - Network issues can be solved } \\
\text { by uploading recorded lectures } \\
\text { after the online sessions. } \\
\text { - PowerPoint presentation slides } \\
\text { should be given prior to class. } \\
\text { - Reduce hours of online } \\
\text { sessions because attention span } \\
\text { during online classes is very low. } \\
\text { - Please make sure that the } \\
\text { professors are well aware of the } \\
\text { platform so that there are not } \\
\text { many technical issues. }\end{array}$ & $\begin{array}{l}\text { - Covering the predefined } \\
\text { curriculum via E-learning is } \\
\text { challenging in terms of content } \\
\text { and time management. The } \\
\text { curriculum should be revised if } \\
\text { E-learning becomes the primary } \\
\text { mode of teaching and learning. } \\
\text { Faculty may be trained in use of } \\
\text { different online platforms as well } \\
\text { as E-learning methods for fruitful } \\
\text { learning. } \\
\text { - It can be used to supplement } \\
\text { but can never replace practical } \\
\text { sessions. } \\
\text { - E-learning and teaching purely } \\
\text { depends on your command of } \\
\text { the subject and taking full control } \\
\text { of the audience with active lively } \\
\text { interaction. }\end{array}$ \\
\hline
\end{tabular}

where faculty delivered the lectures using videoconferencing tools. Many were using these E-learning tools for the first time in their life and took their time in adapting to the new technology. Educators having minimal experience and expertise in E-learning faced various problems in the initial period. With support from the institution and through self-learning, Educators overcame these hurdles.

Education through online platforms ie, E-learning should not be carried out just for the sake of completion of syllabus rather focus on imparting quality education. It should be based on the needs of students and its feasibility. The single lecture should not cross one hour mark as the attention span in the online lecture is difficult to maintain (multiple sessions of short durations are preferred). There 
should be enough gap in between the two lectures, and the total duration of lectures should be limited to three hours in a day as staring at the screen is stressful and exhausting. We hope that these suggestions will help in more effective E-learning.

\section{Limitation of the Study}

The study was conducted in a single institute involving only the MBBS students and a small sample size of Educators. The Learners were not segregated as per their academic sessions.

\section{Conclusion}

The current study highlights the difficulties being faced by the Learners and Educators while conducting online classes. More than half of the students were satisfied with the E-learning and had a positive perception towards its use as a supplement to conventional classroom mode of teaching. Both Learners and Educators had the perception of a moderate degree of agreement about the effectiveness of E-learning. Though the effective delivery of theory content improved over time, delivery of practical aspects of medical education still remains a big challenge. We suggest collaboration of institutes with application developers to create an online inventory of animations, 3D applications and real-time simulation to bridge this gap in delivering practical content.

\section{Acknowledgments}

The authors are thankful to the MBBS students (Batch 2016, 2017, $2018 \&$ 2019) as well as the faculty of AIIMS, Bhubaneswar, who gave their valuable time and participated in the study.

\section{Author Contributions}

All authors contributed to data analysis, drafting or revising the article, have agreed on the journal to which the article will be submitted, gave final approval of the version to be published, and agree to be accountable for all aspects of the work.

\section{Disclosure}

The authors report no conflicts of interest in this work.

\section{References}

1. World Health Organization. WHO Director-General's opening remarks at the media briefing on COVID-19-11 March 2020. March 11, 2020. Available from: https://www.who.int/director-general/speeches/detail/ who-director-general-s-opening-remarks-at-the-media-briefing-oncovid-19-11-march-2020. Accessed September 18, 2021.
2. Government of India. India fights Corona COVID-19. Available from: https://www.mygov.in/covid-19/cbps=1. Accessed September 8, 2021.

3. BBC News. Coronavirus: India enters "total lockdown" after spike in cases. March, 2020. Available from: https://www.bbc.com/news/ world-asia-india-52024239. Accessed September 8, 2021.

4. Government of India. Guidelines on the measures to be taken for containment of COVID-19 epidemic in the country; Ministry of Home Affairs. March 24, 2020. Available from: https://static.pib. gov.in/WriteReadData/userfiles/Guidelines.pdf. Accessed September 8, 2021.

5. Tarkar P. Impact of COVID-19 pandemic on education system. Int J Adv Sci Technol. 2020;29(9):3812.

6. Mamattah RS. Students' perceptions of E-learning. J Online Learn Teach. 2016;11(1):12-38.

7. Welsh ET, Wanberg CR, Brown KG, Simmering MJ. E-learning: emerging uses, empirical results and future directions. Int $J$ Train Dev. 2003;7(4):245-258. doi:10.1046/j.1360-3736.2003.00184.x

8. O'Doherty D, Dromey M, Lougheed J, Hannigan A, Last J, McGrath D. Barriers and solutions to online learning in medical education-an integrative review. BMC Med Educ. 2018;18(1):1-11. doi:10.1186/s12909-018-1240-0

9. Dhir SK, Verma D, Batta M, Mishra D. E-learning in medical education in India. Indian Pediatr. 2017;54(10):871-877. doi:10.1007/s13312-017-1152-9

10. Alkhalaf S, Drew S, Alhussain T. Assessing the impact of e-learning systems on learners: a survey study in the KSA. Procedia Soc Behav Sci. 2012;47:98-104. doi:10.1016/j.sbspro.2012.06.620

11. Olum R, Atulinda L, Kigozi E, et al. Medical education and E-learning during COVID-19 pandemic: awareness, attitudes, preferences, and barriers among undergraduate medicine and nursing students at Makerere University, Uganda. J Med Educ Curric Dev. 2020;7:1-9. doi:10.1177/2382120520973212

12. Amran RS, Muhammad TN, Rashid SN, Hanafi NB, Omar NA, Ismail SM. Students'perception towards online learning during Covid-19 pandemic at Politeknik Sultan Salahuddin Abdul Aziz Shah (PSA). Available from: http://repository.psa.edu.my/handle/ 123456789/2521. Accessed September 18, 2021.

13. Demuyakor J. Coronavirus (COVID-19) and online learning in higher institutions of education: a survey of the perceptions of Ghanaian international students in China. Online J Commun Media Technol. 2020;10(3):e202018. doi:10.29333/ojcmt/8286

14. Sözen E, Güven U. The effect of online assessments on students' attitudes towards undergraduate-level geography courses. Int Educ Stud. 2019;12(10):1-8. doi:10.5539/ies.v12n10p1

15. Kosnin AM, Tan SL. Pengaruh personaliti terhadap kepuasan kerja dan stres kerja guru. J Teknol. 2012;48:33-47. doi:10.11113/jt. $\mathrm{v} 48.244$

16. Nafrees ACM, Roshan AMF, Baanu AN, Nihma MNF, Shibly FHA. Awareness of online learning of undergraduates during COVID 19 with special reference to South Eastern University of Sri Lanka. J Phys Conf Ser. 2020;1712(1):1-11. doi:10.1088/1742-6596/1712/ $1 / 012010$

17. Gupta A, Shrestha RM, Shrestha S, Acharya A, Pandey N. Perception of BDS students of Kathmandu University on online learning during COVID-19 pandemic. OJN. 2020;10(2):20-28.

18. Zalat MM, Hamed MS, Bolbol SA. The experiences, challenges, and acceptance of e-learning as a tool for teaching during the COVID-19 pandemic among university medical staff. PLoS One. 2021;16 (3):1-10. doi:10.1371/journal.pone. 0248758

19. Mohalik R, Sahoo S. E-readiness and perception of student teachers' towards online learning in the midst of COVID-19 pandemic. SSRN Electron J. 2020. doi:10.2139/ssrn.3666914

20. Jang HW, Kim KJ. Use of online clinical videos for clinical skills training for medical students: benefits and challenges. BMC Med Educ. 2014;14(1):1-6. doi:10.1186/1472-6920-14-56 
21. Malkawi E, Bawaneh AK, Bawa'aneh MS, Off C. Education on: UAEU students' satisfaction and attitudes towards E-learning and virtual classes during COVID-19 pandemic. Contemp Educ Technol. 2020;13(1):1-14.

22. Gupta S, Dabas A, Swarnim S, Mishra D. Medical education during COVID-19 associated lockdown: faculty and students' perspective. Med J Armed Forces India. 2021;77:S79-S84. doi:10.1016/j. mjafi.2020.12.008

23. Joshi KP, Jamadar D, Dixit R. Perception of faculty toward online teaching and learning in the undergraduate medical students during coronavirus disease-19 pandemic. Int J Med Sci Public Health. 2020;9(8):484-487.

24. Syed S, Rastogi A, Bansal A, et al. Future of e-learning in medical education-perception, readiness, and challenges in a developing country. Front Educ. 2021;6:1-8. doi:10.3389/ feduc.2021.598309

25. Amir LR, Tanti I, Maharani DA, et al. Student perspective of classroom and distance learning during COVID-19 pandemic in the undergraduate dental study program Universitas Indonesia. BMC Med Educ. 2020;20(1):1-8. doi:10.1186/s12909-020-02312-0
26. Ansar F, Ali W, Khattak A, Naveed H, Zeb S. Undergraduate students' perception and satisfaction regarding online learning system amidst COVID-19 Pandemic in Pakistan. J Ayub Med Coll Abbottabad. 2020;32(4):S644-S650.

27. Rani V, Bethi M. Perception of E-learning among undergraduate medical and dental students during COVID-19 pandemic-A crosssectional study. Natl J Physiol Pharm Pharmacol. 2021;11 (7):671-676.

28. Shete AN, Garkal KD, Somwanshi N. Perceptions of MBBS students regarding E-learning during COVID-19 lockdown. Int J Health Sci Res. 2020;10(9):319-322.

29. Samra RK, Nirola A, Verma A, Nagpal A, Thakur M. Dental students' perception on the impact of E-learning in continuing dental education during the current pandemic scenario. Indian J Dent Sci. 2021;13(2):61-72. doi:10.4103/ijds.ijds_14_21

\section{Publish your work in this journal}

Advances in Medical Education and Practice is an international, peerreviewed, open access journal that aims to present and publish research on Medical Education covering medical, dental, nursing and allied health care professional education. The journal covers undergraduate education, postgraduate training and continuing medical education including emerging trends and innovative models linking education, research, and health care services. The manuscript management system is completely online and includes a very quick and fair peer-review system. Visit http://www.dovepress.com/testimonials.php to read real quotes from published authors. 